\title{
The microhardness and internal stresses allocation in superheating pipes welded node made of dissimilar steels
}

\author{
Aigul Ilyasova ${ }^{1,}$, Roman Kulesh ${ }^{1}$, Lyudmila Lyubimova $^{1}$, Alexander Tashlykov ${ }^{1}$, \\ Anton Gerasimov ${ }^{1}$, Alexander Zavorin ${ }^{1}$, and Evgenii Puzyrev ${ }^{2}$ \\ ${ }^{1}$ National Research Tomsk Polytechnic University, 634050 Tomsk, Russia \\ ${ }^{2}$ Polzunov Altai State Technical University, 656038 Barnaul, Russia
}

\begin{abstract}
The object of research is the welded knot made of dissimilar steels $12 \mathrm{Cr} 1 \mathrm{MoV}$ and Di-59. Research methods are spectral analysis, microhardness measurements and X-ray analysis. It is established that the structural-phase nonuniformity, significant concentration fluctuations of alloying elements, the spread in values of microhardness and mechanical characteristics along the length of the pipe can cause significant value of internal macrostress that leads to the formation of the "flaw" defect type in the welding process. It is shown how to distinguish between flaws that have appeared on the stage of production from operating flaws.
\end{abstract}

\section{Introduction}

Among the broad range of tasks solved in the framework of the Russian energy development, among the first in importance is the problem of ensuring the reliability and efficiency of the thermal power plants equipment.

This applies in particular to those components where in manufacture materials different in their mechanical, chemical, strength and thermal characteristics are used. It is obvious that the most dangerous elements in this sense are welded joints which transitional zone is a kind of stress concentrators.

A characteristic feature of the weld adjacent zone (WAZ) and heat affected zones of welding (HAZ) is the pronounced structural and phase heterogeneity of the properties, which leads to the spread in values of mechanical characteristics in length and the wall thickness of the pipe. This factor in the operational conditions of frequent thermal cycles will create critical temperatures and mechanical stresses, and therefore dangerous surface areas which will impact on the performance of the design as a whole $[1,2]$.

On the other hand, technological modes of pipes production predetermine the appearance of significant discontinuity that will cause a high level of internal structural stresses with reduced material resistance to fracture $[3,4]$.

Control of internal stresses in welded joints is not regulated by the test operation and is not reflected in guidance documents and company standards [5]. However, the recovery

* Corresponding author: asi4@tpu.ru 
heat treatment (RHT), as well as post welding heat treatment (PWHT), the ultimate goal of which is to remove residual stresses, are used as a basis for the extension of material resource and not always clearly guarantees the alignment of properties in transitional areas of the weld [6]. This is due to the fact that the real durability is not determined by design or economic life, but individual physical resource of tubular products from steel and alloys for different purposes.

In this regard, the aim of this research is to identify the distribution of the microhardness and internal structural residual stresses of the first kind associated with a complex of individual properties, ensuring operability of the design.

\section{Materials. Samples. Experimental techniques}

Object of research is weld knot made of dissimilar steels $12 \mathrm{Cr} 1 \mathrm{MoV}$ and Di-59.

Low-alloy heat-resistant structural tube steel $12 \mathrm{Cr} 1 \mathrm{MoV}$ has the following chemical composition according to GOST $20072-74, \%$ by weight: 0.08 to $0.15 \mathrm{C} ; 0.9$ to $1.2 \mathrm{Cr} ; 0.25$ $-0.35 \mathrm{Mo} ; 0.15-0.30 \mathrm{~V} ; 0.4-0.7 \mathrm{Mn} ; 0.17-0.37 \mathrm{Si} ;<0.25 \mathrm{Ni} ;<0.20 \mathrm{Cu} ;<0.025 \mathrm{~S} ;<$ $\mathrm{P} 0.030$; the rest is iron.

A small study of some structural transformations aspects due to the cyclic thermal and mechanical gradients determined the relevance of studies of some materials which seem promising for supercritical pressure boilers superheaters. These include Russian austenitic chord-manganese steel 10Cr13Mg12Si2Ni2Cu2Nb (Di-59).

The chemical composition of the austenitic steel Di-59 according to GOST 5632-72 (\% by weight): $0.07 \% \mathrm{C}$; of $1.99 \% \mathrm{Ni} ; 12.45 \% \mathrm{Cr} ; 13.0 \% \mathrm{Mn} ; 0.21 \% \mathrm{Si} ; 0.006 \% \mathrm{~S} ; 0.015 \%$ $\mathrm{P} ; 0.03 \% \mathrm{Al} ; 2.15 \% \mathrm{Cu} ; 0.79 \% \mathrm{Nb} ; 0.015 \% \mathrm{~B}$; the rest is iron.

As a tool for studies X-ray diffraction, microthermometry and X-ray analysis methods were selected.

Residual stresses of the first kind $\left(\sigma_{\mathrm{I}}\right)$ were defined by Dron-2,0 X-ray apparatus using a radiation tube with a copper anticathode, with an average wavelength $\lambda K \alpha_{\mathrm{av}}=1,54178 \AA$ on the basis of Hooke's law:

$$
\sigma_{\mathrm{I}}=(\Delta a / a) E
$$

где $E$ - modulus of elongation, МПа; $a$ - crystal lattice parameter, $\AA$.

Spectral analysis performed using the EDX 2800 EDXRF spectrometer based on the measurement of the spectra of the chemical elements radiation characteristic in the sample. The elements was identified by the standard perfomance curve provided as element of comparison inherent in the spectrometer program. The resulting spectrum was displayed on the computer, quantitative analysis was performed automatically according to the intensity of the experimental spectral lines and their area.

Measurement of microhardness was carried out using PMT-3 microhardness tester.

Cut-up sketch is shown in Fig. 1, 2. 


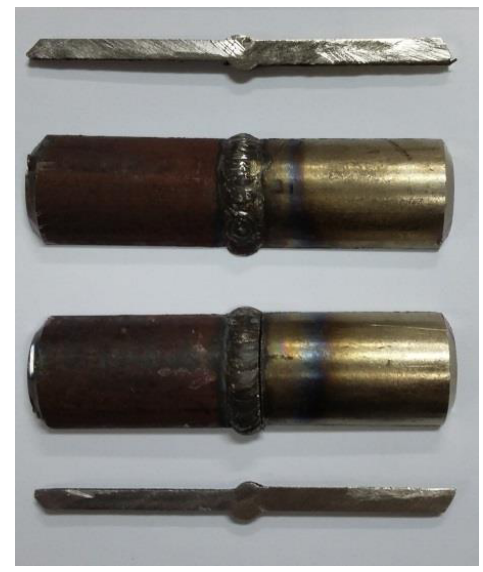

Fig. 1. Cut-up sketch of the longitudinal sample.

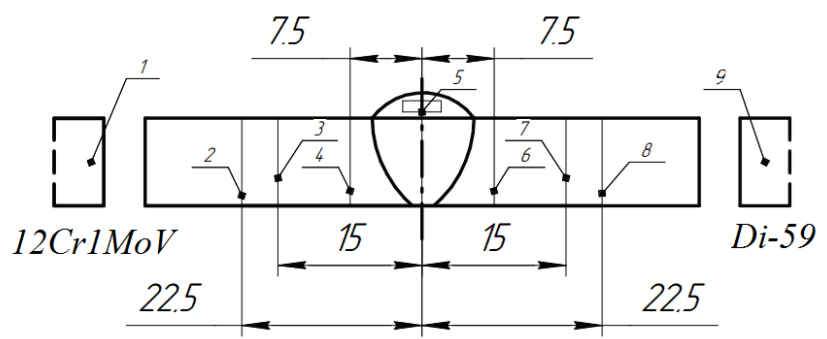

Fig. 2. Cut-up sketch from the transition zones of welded node:

1,9 - reference samples of $12 \mathrm{Cr} 1 \mathrm{MoV}$ and Di-59 steels, respectively;

4, 6 - samples cut from the heat-affected zones at a distance of $7.5 \mathrm{~mm}$ from the axis of the weld; 5 - the sample from the weld zone;

3,7 - samples cut from the heat-affected zones of the weld at a distance of $15 \mathrm{~mm}$ from the weld axis;

2,8 - samples cut from areas at a distance of $22.5 \mathrm{~mm}$ from the axis of the weld.

\section{The experimental facts. Discussion}

Fig. 3, 4 shows X-ray fragments of the weld zone (sample No. 5 in Fig. 2). It is evident that due to weld heat-affected occurs a non-uniform decomposition of the supersaturated solid solution of austenite, which is display itself in the phenomena of structural polymorphism, in the result zone of the weld becomes a mixed phase structure. One of the phases has a body-centred cubic (BCC) lattice $(\alpha-\mathrm{Fe})$, the second phase is an austenite $(\gamma-\mathrm{Fe})$ with face-centered (FCC) lattice. The concentration of the mentioned phases are different for the outer and inner surfaces of the weld zone. 


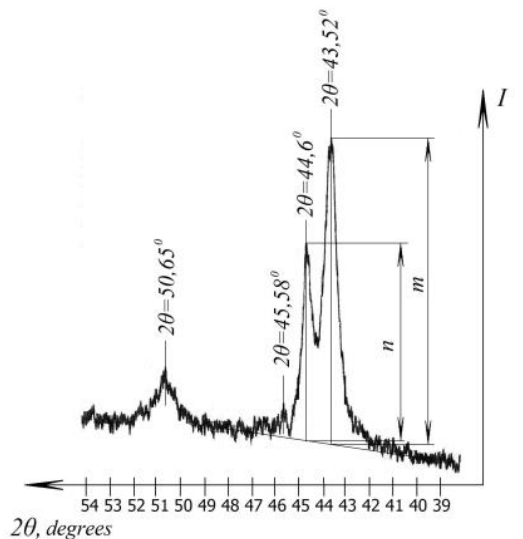

Fig. 3. The outer surface of the weld zone radiographs fragment (sample No. 5).

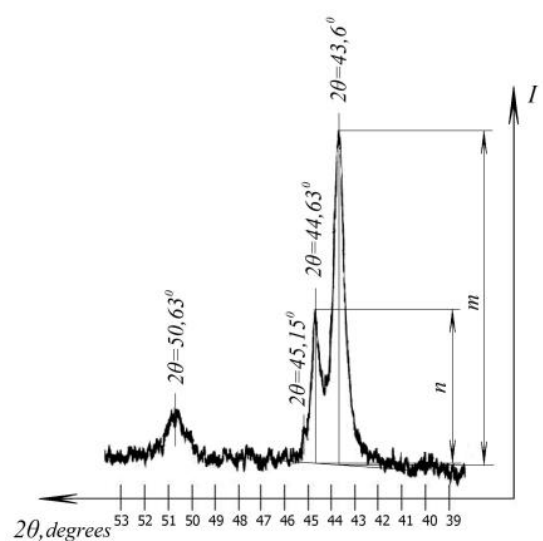

Fig. 4. The inner surface of the weld zone radiographs fragment (sample No. 5).

A consequence of the heterogeneous decomposition of solid solution is the occurrence of point defects in the form of the liberated impurities of substitution and their heterogeneous distribution in the transition and the heat affected zone of the weld (Fig. 5, 6, 7).

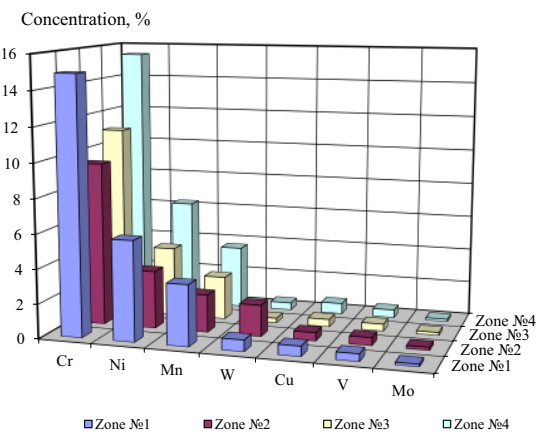

a)

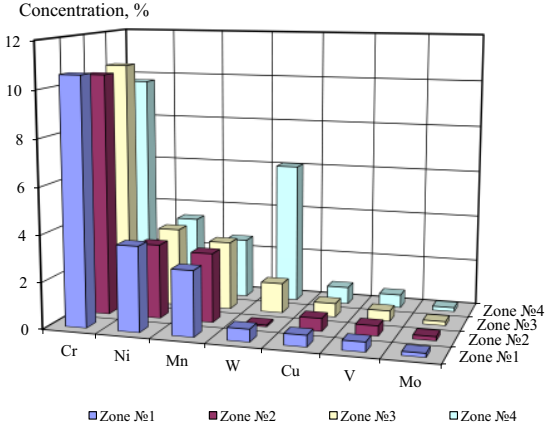

b)

Fig. 5. The results of spectral analysis of the alloying elements distribution in the sample No. 5 (1-4controlled area): a) outer surface; b) inner surface.

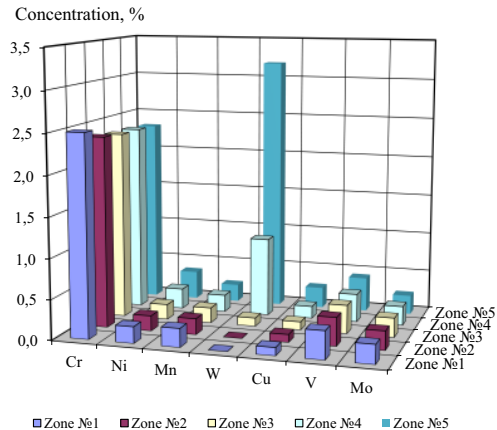

a)

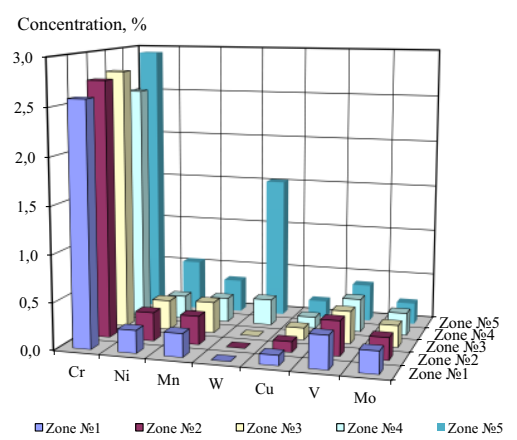

b)

Fig. 6. The results of spectral analysis of the alloying elements distribution in the sample No. 4 (1-5controlled area): a) outer surface; b) inner surface. 


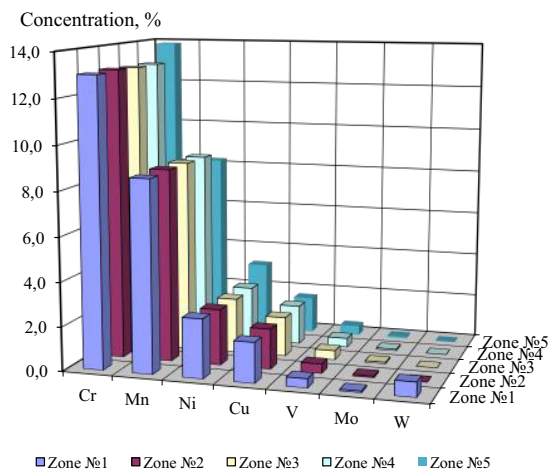

a)

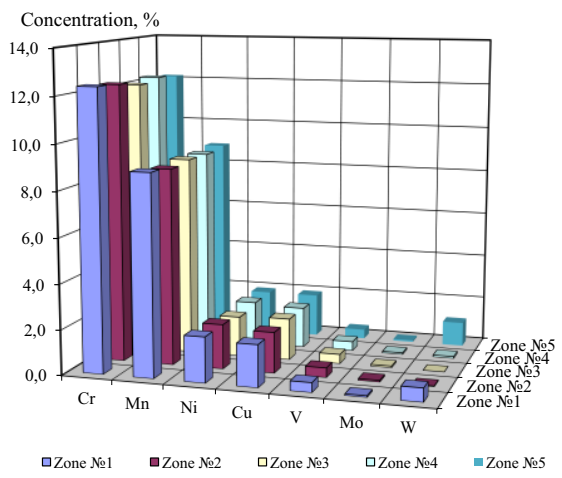

б)

Fig. 7. The results of spectral analysis of the alloying elements distribution in the sample No. 6 (1-5 controlled area): a) outer surface; b) inner surface.

Fig. 8 shows the distribution of microhardness in the welded node. The microhardness was determined for the entire length of the longitudinal sample with a step of $250 \mu \mathrm{m}$ (Fig. 1). Measurement pitch in the area of the weld was $100 \mu \mathrm{m}$.

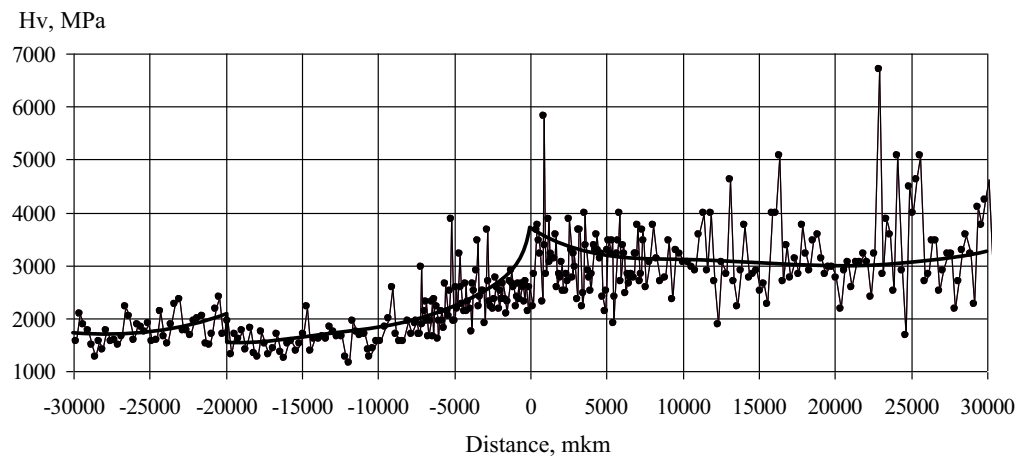

Fig. 8. The microhardness distribution in the longitudinal sample (fig. 1).

The microhardness distribution in the longitudinal sample (fig. 8) allows to conclude:

- thermal influence of welding from $12 \mathrm{Cr} 1 \mathrm{MoV}$ steel side has led to a significant stratification of the pipe wall by the level of microhardness. In particular, at a distance of about 30,000 microns from the axis of the weld, the microhardness corresponds to the level of $2000 \mathrm{MPa}$. Further to the axis of the weld, the level of microhardness increases and reaches a maximum equal to $3500 \mathrm{MPa}$ in the zone of the weld;

- the microhardness of Di-59 steel has a more sharp oscillations from an average value of $3000 \mathrm{MPa}$ to $5000-6000-6500 \mathrm{MPa}$;

- in the immediate area of the weld microhardness varies from $2500 \mathrm{MPa}$ to $3500 \mathrm{MPa}$ in the transition from one steel to another.

The obtained results of the microhardness distribution and alloying elements in the weld zones show the existence of defects, such as delamination of metal - detected zones with high microhardness, reduced creep resistance and soft interlayer.

Structural and phase nonuniformity (Fig. 3, 4), significant fluctuations in the concentration of alloying elements (Fig. 5, 6, 7), the scatter of values of microhardness and mechanical characteristics along the length of the pipe (Fig. 8) are the cause of the significant value of internal macrostress.

Educated estimates of the stress state are shown in Fig. 9. 


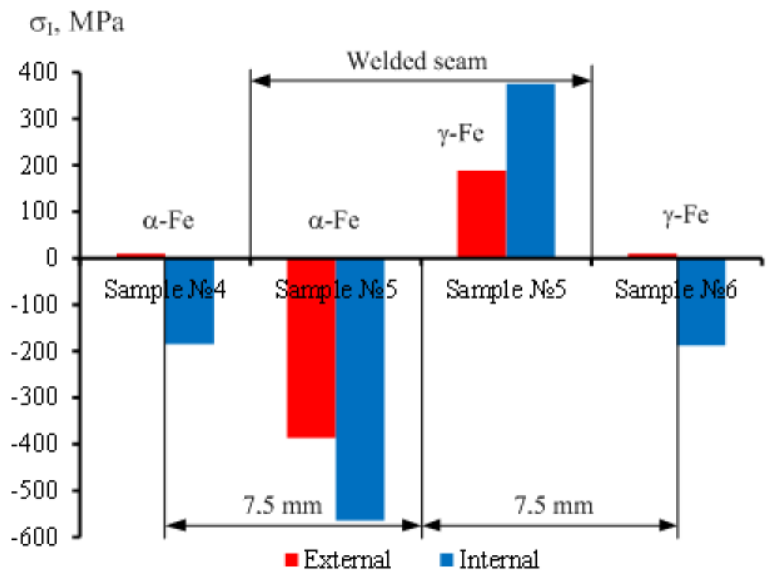

Fig. 9. Scheme of the stress state in the welded node critical zones.

The weld joint thus represents the structure with the presence of structural stresses gradients. A limit state for a typical welding assembly is brittle fracture (Fig. 10). A group of factors such as technological, shape defects, cracks, lack of penetration, contaminants, etc. has a complex influence on initiation of brittle fracture. Significant risk factor for brittle fracture include heterogeneous internal structural stresses which may reach the yield strength [7], and their uneven distribution in the fracture zone [8-12].

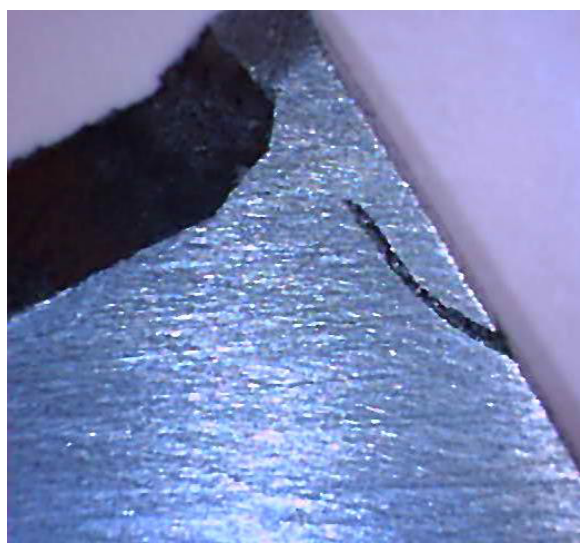

a)

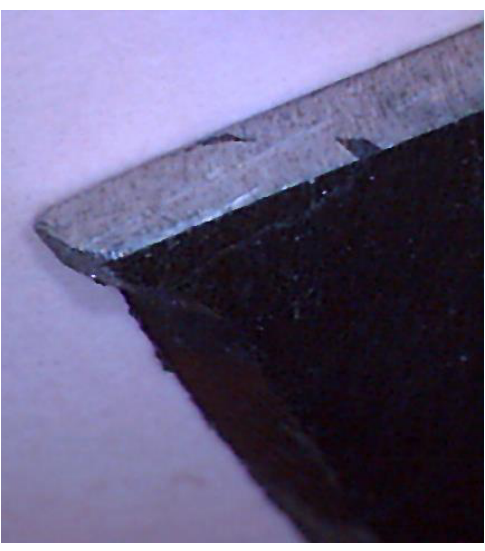

b)

Fig. 10. Crack (x 100) in the HAZ of welded node from the side of $12 \mathrm{KH} 1 \mathrm{MF}$ steel: a) an exterior surface; b) crack propagation along the thickness of the wall in the zone of the weld.

Fig. 10 shows that the crack appeared in the HAZ of $12 \mathrm{Cr} 1 \mathrm{MoV}$ steel (Fig. 10 a) and has spread to the area of the weld (Fig. $10 \mathrm{~b}$ ). This damage may be due to operating conditions, and, most likely, due to the result of the technological process that caused the presence of welding stresses in the joint region of the product caused the formation of primary, steadily growing cracks. How to distinguish cracks appeared on the stage of production from operating cracks?

A sign of the presence of technological cracks that result from the welding process can be relax or compressive stresses in the $12 \mathrm{Cr} 1 \mathrm{MoV}$ steel, indicating a preliminary course of relaxation processes associated with the structural damage. Relaxation is the stress relief 
and the formation of microcracks. The conditions formation in the zone of the weld node is associated with tensile stresses that lead to the initial crack release and its growth.

\section{Conclusion}

1. Revealed significant structural and phase nonuniformity of the structural element having a transition zone of heterogeneous steels in mechanical and thermophysical characteristics.

2. Non-uniform stress concentration in welded node was set.

3. The heat treatment of the welded joint and HAZ of the base metals for the purpose of leveling properties can not coincide, but may lead to a deterioration of the metal actual state and welding structural damage.

This work was supported by RFBR grant "Fundamentals of engineering sciences" No. 15-0899544a in 2015.

\section{References}

1. F.A. Khromchenko, Technology of mechanical engineering, (5), 66 (2007)

2. A.A. Makeev, L.L. Lyubimova, A.S. Zavorin, A.A. Tashlykov, Steel in Translation, 39 (12), 1048 (2009)

3. L. Lyubimova, R. Fisenko, S. Breus, R. Tabakaev, MATEC Web Conf. 72, 01059 (2016)

4. L.L. Lyubimova, R.N. Fisenko, R.B. Tabakaev, A.A. Tashlykov, A.S. Zavorin, Materials Science and Engineering: A, 682, 248 (2017)

5. RD 153-34.1-003-01 "Welding, heat treatment and control of pipe systems of boilers and pipelines during installation and repair of power equipment"' (RTM-1s). 01.01.2002.

6. OS 153-34.17.459-2003. A manual for regenerative heat treatment of thermal power plant equipment elements.30.06.2003.

7. N.I. Kamenskaya, Metallography and heat treatment of metals, 1 (715), 47 (2015)

8. E.A. Grin, A.V. Zelensky, Thermal Engineering, (2), 12 (2009)

9. A.B. Popov, Thermal Engineering, (2), 13 (2011)

10. S.A. Kharchenko, N.B. Trunov, N.F. Korotaev, S.L. Liakishev, Thermal Engineering, (3), 27 (2011)

11. V.V. Gerasimov, O.V. Pereverzeva, Technology of metals, (8), 26 (2008)

12. A.B. Popov Thermal Engineering, (11), 70 (2010) 